\title{
How effective is compulsory schooling as a policy
} instrument?

\section{Changes in compulsory schooling laws have significant effects on certain population groups, but are costly to implement}

Keywords: compulsory schooling, returns to schooling, intergenerational, human capital, signaling

\section{ELEVATOR PITCH}

Compulsory schooling laws are a common policy tool to achieve greater participation in education, particularly from marginalized groups. Raising the compulsory schooling requirement forces students to remain in school which, on balance, is good for them in terms of labor market outcomes such as earnings. But the usefulness of this approach rests with how the laws affect the distribution of years of schooling, and the wider benefits of the increase in schooling. There is also evidence that such a policy has an intergenerational impact, which can help address persistence in poverty across generations.

\section{KEY FINDINGS}

\section{Pros}

$\hookrightarrow$ Opportunity costs of remaining in school may decrease due to compulsory schooling reforms.

๑ Changes in compulsory schooling provide an important tool to estimate the economic return to schooling.

๑ Children of parents who had more schooling due to compulsory schooling reforms may themselves experience benefits.

๑ Indirect benefits from compulsory schooling reforms include lower crime rates and improved mental health outcomes.
School leaving age in England and Wales before and after compulsory schooling reform

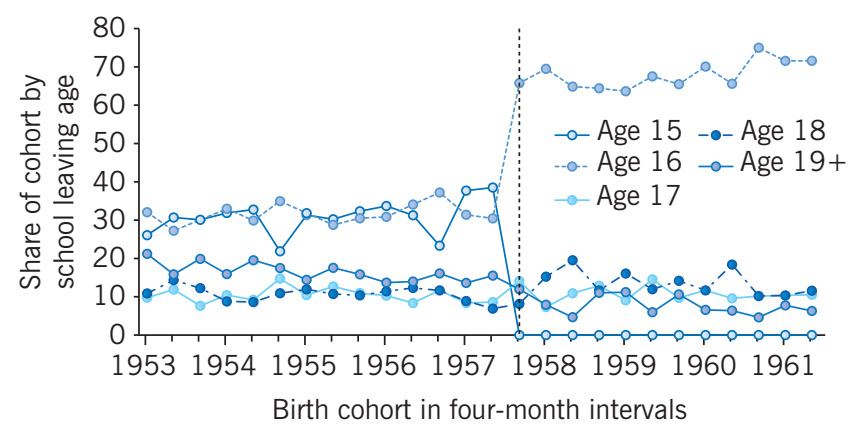

Note: The reform took effect for cohorts born in the final four months of 1957 onwards, indicated by the vertical dotted line.

Source: UK Labour Force Survey, 1993-2012; [1].

\section{Cons}

- While politically convenient, compulsory schooling reforms are expensive.

- Most evidence suggests that the education impact from compulsory schooling is primarily on the most "marginal" students.

- Estimated returns are highest when compulsory schooling reforms encompass an important qualification level, which makes results hard to generalize.

- There is less evidence of wider impacts from compulsory schooling on physical health or mortality rates.

\section{AUTHOR'S MAIN MESSAGE}

The intended impact of a change in compulsory schooling is, by and large, to increase the level of education of those most likely to leave school early; if this is a large cohort and there is strong compliance, it will also raise average schooling levels in the population. The economic return-in terms of earnings-to this schooling can be sizable, which may also have intergenerational returns for the children of those affected by the reforms. Other social benefits, such as crime reduction, improvements in financial literacy, and improvements in mental cognition in older age may also be quite substantial. Less evident are lasting impacts on other private outcomes, such as health. 


\section{MOTIVATION}

Compulsory schooling law changes are paternalistic in nature. In effect, they are based on a presumption that schooling choices (which students and parents make) are worse than they would optimally be for some children. Policymakers see such changes as one way to address persistent economic and social issues, such as improving the educational attainment of those students most "at risk" of dropping out. The policy also remains topical: For instance, the UK is phasing in a variation of compulsory schooling, referred to as a "participation age," which requires students to remain in education or training until the age of 18 .

Any assessment of the policy value of a change in compulsory schooling requirements crucially depends on whether such change delivers on its underlying policy driver: increasing the minimum education level in the population. Alternatively, the change may just have an impact on an important but distinct group: those most likely to leave school early. The primary issue is whether or not the impact of the reform is enough to generate sizable labor market returns for those impacted by it. It is also important to consider whether or not other benefits (private or social) associated with increased educational attainment are generated, such as increased financial literacy, better health outcomes, or reduced probability of being involved in crime. In general, however, analysis of the impact of compulsory schooling has not accounted for the often quite substantive questions of schooling quality that may arise, such as contemporaneous revisions in curriculum standards which change what is actually taught to students, or the impact of student cohorts being retained in existing schools without commensurate changes in the number of teachers or in the buildings/facilities on school campuses.

\section{DISCUSSION OF PROS AND CONS}

\section{Compulsory schooling and the educational distribution}

If a low-productivity (and low-educated) group raises its education level because of a policy intervention such as a compulsory schooling law change, a signaling model would suggest that more productive (and currently better educated) groups may also want to invest in additional education to continue to distinguish themselves from the less productive, and so continue to secure the limited pool of higher wage jobs. However, in a human capital model, schooling is considered an investment in human capital, so a compulsory schooling change forces the lower-educated to be more productive, raising their wages without any impact on the schooling decisions of others.

The distinction between these two outcomes is critical to understand the policy potential of compulsory schooling laws. In a human capital model, compulsory schooling laws will only have an impact on the level of schooling of the lowest educated in the population. This is a significant policy result-it creates a "local" effect on a marginal group that, in some countries, is a very large cohort. It may also have some impact on the probability of leaving school with a formal qualification, such as a high school diploma. In a signaling explanation, a change in the compulsory level raises the overall population average.

Discovering what happens when a compulsory schooling law is introduced is critical to understanding the wider impact of a change in the quantity of education. This can be illustrated using the experiences of England and Wales, where there have been two 
increases in the minimum school leaving age, in 1947 and in 1972. Prior to the 1972 reform, which raised the minimum school leaving age from 15 to 16 , close to $25 \%$ of the cohort left at the prevailing minimum of 15 , whilst immediately after the reform compliance was high and less than $5 \%$ were recorded as leaving at 15 (see the illustration on page 1). In addition to higher attendance, the reform brought the compulsory level to what is typically an examination year, so the numbers of students classified as having "no qualification" dropped sharply, and a consequential rise in those reporting a formal high school qualification (the "O-level") was observed. Increasing the compulsory level moves one group further up the distribution by around a year, but the impact beyond that point on the educational distribution is more muted. This is confirmed in an examination of various changes in compulsory schooling laws over the period following the Second World War in 12 European countries, where, on average, a change in compulsory schooling translates into 0.3 to 0.4 years of additional education for individuals at the lower end of the distribution, and this falls to 0.1 years for the rest of the population [2].

\section{Compulsory schooling and earnings}

Estimating the causal impact of schooling on earnings is challenging because of the "simultaneous" nature of the relationship between education choices and earnings. Unobservable characteristics (such as motivation) associated with education choices may also be associated with earnings outcomes, making the relationship between the two difficult to establish. Compulsory schooling laws provide an important tool to estimate the economic return to schooling, as they act as a "shock" of sorts to an individual that is outside of their direct control.

As seen in the illustration on page 1, those born in England and Wales in 1957 would have faced an extra year of compulsory schooling if they were born in the final third of the year compared to the earlier part of the year, as a result of the 1972 reform. Individuals born in the latter part of 1957 had a significant additional level of enforced schooling for reasons that were, in effect, random (i.e. determined by their date of birth, which is outside their control). A very sizable literature has developed exploiting these changes as a means to estimate the returns to schooling. In an over-simplified characterization of the evolution of this literature, the critical issue rests with what is being estimated: the rate of return for all individuals, or the rate of return for those individuals affected by the changes in schooling laws (i.e. typically those who are most marginal in their schooling choices). The literature now favors the latter-a "local" average treatment effect (or LATE) interpretation. The change in compulsory schooling alters the schooling decision for a particular cohort: the schooling of those always likely to stay on (or, indeed, never likely to stay on) remains unchanged, but others get more schooling as a result.

For example, research focused on the UK exploits an education market characterized by large cohorts of early school leavers at the time of the changes in compulsory schooling. This may result in larger estimates of the return to compulsory schooling-often doubling in magnitude compared to simple estimates [3]. These higher returns could be interpreted as suggesting that those who value education least, and so leave early, will actually gain the most from staying in school [4]. However, this is not a universal result and the spread of estimates produced by this literature is significant. Other research based on changes in compulsory schooling (in the Nordic countries, France, and some reanalysis of UK and US 
data) find little or no difference in earning returns compared to simple regression models of the average return.

Analysis of UK data focusing solely on the 1947 reform produces estimates of earnings returns for men that are consistent with the simple "average" estimates, and zero returns for women. With a larger cohort of early leavers than in the later 1972 reform (because the 1947 was delayed in its introduction-the guiding act was passed in 1944), estimates of the "local" effect are a closer reflection of the "average" effect for the population at large [5]. One explanation that can potentially reconcile conflicting findings on the 1972 UK reforms is that, unlike the 1947 reforms, students forced to remain until the end of the academic term following the 1972 reforms were more likely to obtain formal qualifications, which is reflected in the differences in returns to schooling after the two reforms. The implication is that the quality of schooling-reflected by the credential in this case-is as important as the quantity.

An alternative perspective, which more closely resembles the signaling approach, is that low private returns in the labor market may indicate the limited return to additional schooling, particularly when it comes to wages, and that leaving school early is therefore a rational choice. In effect, the individuals affected by changes in compulsory schooling are those with inherently low earnings returns. This is similar to the arguments presented for Germany, where the estimated return to compsulory schooling is zero [6]. This research focuses on the tracking of students into vocational or academic streams at early ages. The academic stream students have attained relatively basic skills by the time they reach the compulsory schooling age, whereas their peers in the vocational stream (which is unaffected by the reforms in their analysis) have attained employment-oriented skills by the same age with appropriate returns in the labor market. The zero returns to additional compulsory schooling rest on the claim that students in the academic stream do not have the labor market-relevant skills upon leaving school.

Institutional factors more common in European labor markets, such as relatively high minimum wages and high unionization, may also affect returns to compulsory schooling (by, for example, raising the earnings from relatively low levels of schooling). Similarly, the Nordic countries often changed the minimum schooling level to reflect underlying trends within their population (i.e. students were already remaining in school beyond the minimum age), rather than to enforce any new norm. On this question-the role of the underlying system and cohort trends in participation-recent research compares schooling age reforms in the UK and France. In many European countries, the school curricula are often structured to allow each level of study to lead to a specific credential, and, in the author's interpretation, the 1972 changes in England and Wales yielded positive wage returns because they brought the cohort to a year in which a credential was typically taken-in effect a quality enhancement from the additional year. This was in contrast to the French case, whose 1967 "Berthoin" reform was not explicitly designed to reduce the fraction of pupils leaving school without any academic qualification [7].

To summarize this important question-what is the rate of return to earnings from compulsory schooling? - it appears to be at least as big as the average return to schooling in general, but may in fact be much larger. Even allowing for the variance in returns observed in the literature, the returns from compulsory schooling may still imply poor choices by some individuals. But the estimation of the return to compulsory schooling points to a set of important policy questions. The focus of policy to encourage educational participation 
among low socio-economic status (SES) cohorts is often pecuniary in nature, with low participation viewed as being the impact of a financial constraint acting as a barrier to further participation. However, one interpretation of the high rate of return to compulsory schooling is that it provides an estimate of the discount rate being applied by early-leavers (it indicates that early-leavers value the present over the future). For example, recent evidence with linked administrative data for a UK cohort from age 11 to 19, finds that poor attainment in secondary school is more important in explaining lower participation rates in higher education amongst students from disadvantaged backgrounds than income/ credit constraints.

In this context, some form of conditional cash transfer for participation may lower the "opportunity cost" of staying on, encouraging those most likely to leave early to remain in school. The payment may change the trade-off between return and risk for youths with a high discount rate for time. As an example of such a policy from the UK, Educational Maintenance Allowances (EMAs) provided a sizable means-tested cash benefit conditional on participation in post-compulsory (age 16 in this instance) education. Evaluations of the EMA policy trials show enrollments increased by up to $6 \%$ in families eligible for full subsidies. Of course, one cannot be sure of the extent to which this extra education is valuable to these participants. If unmotivated students are encouraged to remain in school, a conditional cash transfer policy such as the EMA may be an inefficient use of resources. But the findings suggest that a better explanation for dropout behavior may be that early leavers are myopic, and that there is a limited potential for money to encourage post-compulsory participation [8].

This creates a very interesting challenge for policymakers to change how early leavers value the options they face. A behavioral approach to encouraging participation may be more successful. For example, recent US research uses an experimental design to examine the impact of assistance on addressing the complexity of the financial aid process for college applications. In the full treatment group, who received assistance with the application process as well as personalized information (such as pre-filled forms based on tax return information), college entry rates increased by $24 \%$ for high school seniors; they also had significantly more time in college when audited three years after entry than the control groups. With a relatively low financial cost (in the region of US $\$ 100$ per participant), the returns from this relatively simple "nudge" are large. In the spirit of this research on the behavioral economics of education, compulsory schooling laws serve as a means to set and alter the expectations of students.

\section{Compulsory schooling: Intergenerational impact}

Inequity across the socio-economic gradient in key outcomes for children-including educational attainment-is the focus of considerable policy attention. While the intergenerational relationship between children and their parents is well-known, establishing the causal links is important for targeting policy recommendations. For example, it is important to determine whether the transmission mechanism works through inherited genetic factors or environmental factors (the so-called nature/nurture debate) and, to the extent that it is the latter, what is the relative importance of parental education and income?

Given that a change in compulsory schooling is an exogenous "shock" to the individual, it provides researchers with an important tool to examine the impact of parental 
schooling (which is changed due to reforms affecting their compulsory level) on the outcomes of children. The implication is that the increase in parental schooling has a positive impact on parental earnings, which feeds through to their children's schooling attainment via better schools, better home environments, and so on. Taking the UK estimates in [1], one extra year of parental schooling (of the father in this case) reduces the dropout probability of the child by $7 \%$. Given an average gap in education between dropouts and non-dropouts of up to two years, this translates into an increase of approximately 0.14 years of schooling for the child. If the return to schooling is $10 \%$, an increase in parents' compulsory schooling could raise the wages of children by $1.5 \%$. Based on US Census data and state-by-state variation in compulsory schooling laws and their changes, one study examines the role of the change in parental education on their children's tendency to repeat high school grades. The authors show that a oneyear increase in the schooling of parents lowers the probability of repeating high school grades by between two and four percentage points against an average repeat "rate" of $15 \%$. This basic result is robust across other specifications and schooling measures such as dropout rates [9].

\section{Compulsory schooling and wider outcomes}

Despite the widely observed correlation between better health (including specific biomarkers such as those for heart disease or diabetes) and more education, the causal nature of this relationship is harder to pin down. For this reason, the exogenous change from a compulsory schooling law can provide useful evidence on the health and education relationship.

Based on an analysis of compulsory schooling changes in seven European countries (Austria, the Czech Republic, Denmark, England, France, Italy, and the Netherlands), one additional year of schooling decreases the probability of self-reported poor health by about 5 percentage points for men, and by between 4 and 6.4 percentage points for women. These results are somewhat larger than the simple ordinary least squares estimates of the health "return" to schooling, suggesting that some underestimation of the impact of education on health has previously occurred, but they are also larger than the findings based on the UK reforms. Using various UK data sets, one study finds quite modest returns to actual physiological measures of health outcomes (such as blood pressure), mortality rates, as well as self-reported health outcomes and health behaviors. The authors suggest that the additional schooling may come too early to have a lasting impact on health choices and outcomes, making the causal relationship impossible to determine [10]. This is consistent with the view that reforms which happened in the early part of the century had a larger effect on health outcomes such as mortality because they reduced the likelihood that children would be employed in physically intensive employment, which would lead to poor physical health later in life.

A related-but contrasting-interpretation drawing on the early education investment literature is that the change in schooling actually comes too late. The emerging synthesis between economics and biological research would suggest that early interventions will "hard-wire" health trajectories epigenetically, and as such a schooling change in mid-teens will not have any impact. Overall there appears to be weak evidence to motivate a policy such as compulsory schooling on the grounds of a lasting physical health impact. 
A somewhat different but related outcome is mental health. With strong support for the correlation between education and mortality, including the specific impact from the additional education generated by compulsory schooling changes, the health care costs of an aging population may be offset if there is a specific impact of schooling on delaying cognitive decline conditional on survival (what geriatricians sometimes refer to as "successful aging"). Research based on the Survey of Health, Ageing and Retirement in Europe (SHARE) database of older adults in Europe, and the same country reforms discussed in [2], examines the impact of compulsory schooling on depression and cognition (as measured by a word recall test). The additional schooling reduces the probability of suffering depression by 6.5 percentage points, with also a significant impact on cognition [11]. These findings support earlier work on the English Longitudinal Study of Ageing (ELSA) which shows a positive and significant causal effect on old-age memory of lesseducated people based on the impact of the 1947 UK reforms.

A promising related strand of research uses compulsory schooling to identify the role education plays in key cognitive choices. One study demonstrates how schooling has a causal impact on financial outcomes (like income): By exploiting changes in compulsory schooling the authors show that each additional year of schooling increases investment income by US\$1,760. However, it also has a significant impact on financial decisionsimproving financial literacy. More-educated individuals have fewer financial complications, higher credit scores, and lower probability of mortgage re-financing. The probability of having any retirement income rises by $5.9 \%$ for each additional year of schooling, while lowering the probability of bankruptcy by 0.2 percentage points (a small but statistically significant and robust result). Interestingly, these results control for whether or not the student has studied financial literacy at school through courses in personal finance, but this additional training does not have a significant impact on financial decision making. This implies that the mechanism for improved financial decision making rests with changes in numeracy and basic mathematics/statistics capacity-the additional schooling from changes in compulsory levels has an impact through enhanced numeracy [12].

In another application, compulsory schooling changes provide a potential identification strategy to examine how education and crime are related. A number of channels exist for education to influence crime outcomes. For instance, increased earnings raise the opportunity costs of illegal behavior. Education may also limit the time available for criminal activity. Finally, harking back to the earlier discussion on discount rates (or time preferences), more-educated individuals may value the future more than the present, and may be more risk averse-neither of which are associated with criminal behavior. Using the UK reforms to estimate the causal relationship between education and crime, one study finds an almost 5\% reduction in the conviction rate in the years following the 1972 reform, and in the full econometric model a $10 \%$ increase in school leaving age lowers crime by $2.1 \%[13]$.

\section{LIMITATIONS AND GAPS}

In many of the health focused studies, the data do not give clear evidence on the transmission mechanism for these effects. The examination of an aged-population cohort is limiting of itself (although ongoing work which links data sets like ELSA to administrative records will open up new opportunities for analysis). The SHARE data is very rich in controls but, unfortunately, the sample sizes are too limiting to allow for the 
impact of additional schooling to be estimated for different sub-populations. Ultimately, it is not clear whether the schooling reform increased earnings, which, in turn, provided a better social environment through "cognitively" rich activity (such as being able to afford membership of social/sporting clubs), or whether the cohort impacted by the reform had more cognitively demanding occupations by virtue of their enhanced schooling, which helped offset later-life cognitive decline.

With respect to the evidence on intergenerational returns, compulsory schooling reforms increase education at the left (low schooling) tail of the distribution, but it is also likely that a policy change that increased enrollment in higher education would have a larger intergenerational impact through, inter alia, increased parental earnings. Furthermore, in this literature there may be issues related to the underlying social and educational structures. The US studies tend to show larger impacts from a change in parental schooling on child outcomes compared to, say, Nordic studies. One interpretation is that the difference is related to the higher average return to education in the US (so the larger impact on the child comes through a sizable parental income effect). In Norway and Sweden, the greater availability of high-quality publicly funded education (which dampens the additional impact of parental investment) lowers the intergenerational returns.

\section{SUMMARY AND POLICY ADVICE}

Raising the compulsory schooling level is a policy option that has been utilized by many countries. By and large, the evidence shows that this raises the education of those most likely to leave early, but with some potential for positive impact further up the educational distribution. It also has strong potential for intergenerational effects as well as other outcomes such as health and crime. The impact of that increased education on individuals' earnings is mixed, but is largest when changes in compulsory schooling impact a large cohort and/or lower the likelihood of dropping out without a qualification.

It is, however, not a costless policy. The UK reforms from the 1970s, for example, required a large (and ultimately somewhat haphazardly managed) provision of additional teaching capacity, including physical space, which was often provided in temporary buildings that remained in use long after the reforms were introduced. Raising the compulsory schooling level places strain on the school system, and, moreover, may have some impact on the quality of education (e.g. due to larger class sizes or because potentially less motivated students retained in compulsory school incur negative externalities for the wider school population). Data from the New South Wales state government in Australia place the costs of the 2010 changes in compulsory schooling (from age 15 to 17) at about an additional $A \$ 100$ million per annum, with the salaries of additional teaching staff making up $60 \%$ of that figure. This represents a permanent $1 \%$ increase in their total annual expenditure on education. The relatively low cost in this case reflects that the actual average schooling level had largely exceeded the compulsory level in New South Wales, so the cohort affected by the reform is not likely to be very large. By contrast, the costs of the reforms that took place in the UK in the 1970s-where the size of the affected population was more substantial-are likely to have been much larger. More recent reforms aimed at reducing the number that are not in education, training, or employment, such as the UK's efforts to extend schooling of some form (including apprenticeships) to age 18, will generate quite substantial costs for the formal school sector as well as the further education and training sectors. 
The basic issue for policymakers facing these costs is whether compulsory schooling reform is an efficient policy choice. If individuals are unaware of the benefits of more education, the case for public policy intervention is stronger. The private returns to the individual in terms of higher earnings and lower probability of exiting school without qualifications has an impact on public finances through lower welfare dependency and higher income taxes, and this is likely to be reinforced over generations. Moreover, the potential for other benefits to substantively outweigh the reforms' direct costs is likely to be larger. As noted by [13], the social benefits from crime reduction that would follow from a $1 \%$ reduction in the percentage of individuals with no educational qualifications would reduce the number of property crime offences by as much as 45,000 -generating social benefits in excess of $£ 60$ million against their estimated costs of $£ 20$ million to achieve the $1 \%$ reduction.

A focus on increasing participation through raising the minimum schooling level could indeed be a more efficient policy direction, with less of the deadweight effects of subsidybased strategies. Increased compulsory schooling would also benefit future generations through intergenerational transmission of the benefits of higher levels of schooling among parents to their children. It also fits with a more behavioral approach to addressing educational choice. The evidence suggests that some cohorts are making poor choices in terms of their futures and choosing more immediate gain over the more valuable longterm returns to education. This is a challenge, in that it requires a more targeted approach than policymakers tend to prefer, and a move away from a dependency on welfare and other financial subsidies to encourage better schooling choices.

\section{Acknowledgments}

The author thanks an anonymous referee and the IZA World of Labor editors for many helpful suggestions on earlier drafts. Previous work of the author contains a larger number of background references for the material presented here and has been used intensively in all major parts of this article, including [1] and [3]. Financial support from the Australian Research Council (ARC) Centre of Excellence for Children and Families over the Lifecourse is gratefully acknowledged.

\section{Competing interests}

The IZA World of Labor project is committed to the IZA Guiding Principles of Research Integrity. The author declares to have observed these principles.

(c) Colm Harmon 


\section{REFERENCES}

\section{Further reading}

Harmon, C. P, H. Oosterbeek, and I. Walker. "The returns to education: Microeconomics." Journal of Economic Surveys 17:2 (2003): 115-155.

Oreopoulos, P., and K. G. Salvanes. "Priceless: The nonpecuniary benefits of schooling." Journal of Economic Perspectives 25:1 (2011): 159-184.

\section{Key references}

[1] Chevalier, A., C. P. Harmon, V. O'Sullivan, and I. Walker. "The impact of parental income and education on the schooling of children." IZA Journal of Labor Economics 2:8 (2013): 1-22.

[2] Brunello, G., M. Fort, and G. Weber. "Changes in compulsory schooling, education and the distribution of wages in Europe." The Economic Journal 119:536 (2009): 516-539.

[3] Harmon, C. P., and I. Walker. 1995. "Estimates of the economic return to schooling for the United Kingdom." The American Economic Review 85:5 (1995): 1278-1286.

[4] Oreopoulos, P. "Estimating average and local average treatment effects of education when compulsory schooling laws really matter." American Economic Review 96:1 (2006): 152-175.

[5] Devereux, P., and R. A. Hart. "Forced to be rich? Returns to compulsory schooling in Britain." The Economic Journal 120:549 (2010): 1345-1364.

[6] Pischke, J.-S., and T. von Wachter. "Zero returns to compulsory schooling in Germany: Evidence and interpretation." Review of Economics and Statistics 90:3 (2008): 592-598.

[7] Grenet, J. "Is extending compulsory schooling alone enough to raise earnings? Evidence from French and British compulsory schooling laws." The Scandinavian Journal of Economics 115:1 (2013): 176-210.

[8] Oreopoulos, P. "Do dropouts drop out too soon? Wealth, health and happiness from compulsory schooling." Journal of Public Economics 91:11-12 (2007): 2213-2229.

[9] Oreopoulos, P., M. E. Page, and A. Stevens. "The intergenerational effects of compulsory schooling." Journal of Labor Economics 24:4 (2006): 729-760.

[10] Clark, D., and H. Royer. "The effect of education on adult mortality and health: Evidence from Britain." American Economic Review 103:6 (2013): 2087-2120.

[11] Crespo, L., B. López-Noval, and P. Mira. "Compulsory schooling, education, depression and memory: New evidence From SHARELIFE." Economics of Education Review 43 (2014): 36-46.

[12] Cole, S., A. Paulson, and G. K. Shastry. "Smart money? The effect of education on financial outcomes." Review of Financial Studies 27:7 (2014): 2022-2051

[13] Machin, S., O. Marie, and S. Vujić. "The crime reducing effect of education." The Economic Journal 121:552 (2011): 463-484.

\section{Online extras}

The full reference list for this article is available from:

http://wol.iza.org/articles/how-effective-is-compulsory-schooling-as-a-policy-instrument

View the evidence map for this article:

http://wol.iza.org/articles/how-effective-is-compulsory-schooling-as-a-policy-instrument/map 